ISSN: $1130-3743$

\title{
LA EXPERIENCIA DE LAS VÍCTIMAS EN EL DISCURSO PEDAGÓGICO
}

\section{The experience of victims in the pedagogical discourse}

\section{L'expérience des victimes dans le discours pédagogique}

Pedro OrTega Ruiz* y Eduardo Romero SÁNCHEZ**

Facultad de Educación. Departamento de Teoría e Historia de la Educación. Universidad de Murcia. Campus Universitario de Espinardo. Murcia.

Correo-e: "portega@um.es; **eromero@um.es

Fecha de recepción: enero de 2013

Fecha de aceptación definitiva: abril de 2013

Biblid [(1130-3743) 25, 1-2013, 63-77]

\section{RESUMEN}

En este artículo los autores señalan la deuda contraída por el discurso pedagógico con los excluidos de la sociedad. La violencia y marginación producidas por las distintas formas del totalitarismo no han encontrado espacio en la preocupación de los pedagogos. Una pedagogía anclada en la Ilustración y la ética kantiana no han hecho posibles un discurso y una educación solidarios con la suerte de los desfavorecidos y diferentes culturales. Hay otra ética (levinasiana) enraizada en el sentimiento que puede servir de soporte para una pedagogía de la acogida y de la compasión. Los autores propugnan una pedagogía que contempla a un sujeto histórico en toda su realidad; una educación atenta a la situación de cada educando en la singularidad de su existencia.

Palabras clave: educación, ética, acogida, experiencia, víctima, discurso. 
SUMMARY

In this article the authors point out the debt acquired by the pedagogic discourse with those excluded from society. Violence and marginalization caused by different ways of totalitarianism have not found room in the concern of educators. A pedagogy rooted in the Illustration and Kantian ethics have not made possible a speech nor an education which support the fate of the disadvantaged and cultural differences. There is another ethics (Levinas) rooted in the feeling which can provide support for a pedagogy of reception and compassion. The authors propose a pedagogy that considers a historical individual in all their reality, an education responsive to the situation of each student in the uniqueness of their existence.

Key words: education, ethics, acceptance, experience, victim, discourse.

\section{SOMMAIRE}

Dans cet article, les auteurs signalent la dette prise par le discours pédagogique avec les exclus de la société. La violence et la marginalisation causées par les différentes formes de totalitarisme n'ont pas fait partie du souci des éducateurs. Une pédagogie ancrée dans le siècle des Lumières et l'éthique kantienne n'ont pas rendu possible un discours et une éducation solidaires avec le sort des défavorisés et les différences culturelles. Il y a une autre éthique (Levinas) enracinée dans le sentiment qui peut fournir un soutien pour une pédagogie de l'acceptation et de la compassion. Les auteurs défendent une pédagogie qui envisage un sujet historique dans toute sa réalité, une éducation adaptée à la situation de chaque élève dans la particularité de son existence.

Mots clés: éducation, éthique, acceptation, expérience, victime, discours.

Un siglo marcado perdurablemente por el odio hacia el otro hombre, el desprecio cotidiano hacia él y la sordera ante su llanto somete a todos a la tentación del nihilismo, una de cuyas crueles vicisitudes es el individualismo de las sociedades occidentales (C. Chalier [1995], La utopia de lo bumano, p. 9).

\section{INTRODUCCIÓN}

"Que Auschwitz no se repita" es el nuevo imperativo categórico propuesto por Adorno. El imperativo adorniano nos impone una nueva mirada ante las humillaciones presentes; nos exige el ejercicio constante de la crítica ante la persistencia de las condiciones que hicieron posible aquella catástrofe. Lejos de convertirnos en estatuas de sal atrapadas por el tiempo, este imperativo "moviliza el recuerdo solidario con las víctimas, la memoria de las esperanzas incumplidas y las injusticias pendientes de resarcimiento contra todo aquello que sigue produciendo dolor y sufrimiento, aniquilando a los individuos" (Zamora, 2004, 15). Después de 
Auschwitz ya no cabe la inocencia, ni el optimismo que ocultaba las profundas contradicciones de una sociedad que había puesto sus esperanzas en el proceso emancipador de la Ilustración. Las promesas incumplidas de libertad y justicia no se debieron a fuerzas "extrañas", su fracaso tiene su origen en la naturaleza misma de la Ilustración, en el principio de dominación, consustancial a la razón moderna (Horkheimer y Adorno, 1994). El Holocausto es una criatura de la sociedad moderna y racional, nació en un momento álgido de nuestra cultura y es un problema de esa sociedad y de esa cultura (Bauman, 1997), que sigue siendo hoy también la nuestra. Quizás, la explicación de los males sociales de hoy pueda encontrarse en el omnipresente pensamiento ilustrado, es decir, en las relaciones de los individuos con la naturaleza y de los individuos entre sí, "relaciones que han estado presididas por el principio de identidad que somete coactivamente lo diferente, singular y múltiple, que ejerce violencia sobre su otro, lo no idéntico" (Zamora, 2004, 16). Es la razón instrumental, hija de la racionalidad ilustrada, la que ha estructurado la sociedad moderna y se ha convertido para el hombre en el criterio principal, cuando no en el único, que decide y justifica, en la práctica, los comportamientos sociales, económicos y políticos. Esta mentalidad instrumental, que caracteriza a la sociedad moderna, ha penetrado profundamente en todas las estructuras sociales y ha configurado todo un estilo de vida. El ser humano ha pasado a ser un objeto que tiene un precio, se ha cosificado. Habermas (1996, 140), comentando a Horkheimer, se hace eco de este hecho: «Las propias ideas (en el sentido kantiano) se ven arrastradas por el remolino de la cosificación; hipostatizadas y convertidas en fines absolutos, sólo tienen ya un significado funcional para otros fines... la verdad y la moralidad se ven privadas de su contenido incondicionado".

No establecemos aquí equiparación alguna entre el Holocausto y las condiciones extremas de miseria y pobreza en las que viven millones de nuestros conciudadanos. Sería una forma de banalizar el mal radical que representa Auschwitz. Sí afirmamos que la experiencia de inbumanidad que representa Auschwitz nos obliga a pensar la ética no a partir de la idea del "bien", sino a partir de la experiencia del mal; nos obliga a plantearnos la necesidad de establecer unas relaciones sociales nuevas, distintas, en las que la diferencia y la singularidad puedan encontrar cauces de expresión y promoción en la sociedad, unas relaciones éticas en las que el principio de dominación no se imponga sobre los individuos convirtiéndolos en dominadores y dominados, en señores y esclavos. Afirmamos que las ideas que hicieron posible Auschwitz permanecen hoy y "explican" el expolio y humillación de tantas víctimas inocentes; que el discurso moral dominante en nuestras aulas y en nuestras publicaciones es el reflejo de la conciencia moral de nuestra sociedad que, lejos de constituir una crítica ética a la misma, cumple una función legitimadora de este modelo de sociedad. Los múltiples genocidios de la Era Moderna, las perversas formas de embrutecimiento que impone a los individuos el capitalismo salvaje "no permiten albergar dudas sobre la existencia de un vínculo entre Modernidad y barbarie, incluso sobre la existencia de una barbarie específicamente moderna" (Zamora, 2004, 23). 
La ética idealista se ha mostrado del todo insuficiente para dar una respuesta a aquella catástrofe, y es insuficiente para responder ahora a las situaciones de exclusión y violencia que afectan al hombre de hoy. No es en una situación «ideal" de diálogo en la que se dirime la suerte de nuestros conciudadanos, sino en su condición histórica de seres concretos, afectados por la violencia que ejercen aquellos que detentan el poder.

Pero no sólo la ética, también la educación, después de Auschwitz, nos obliga a una crítica radical, no sólo de nuestra práctica educativa, sino de las fuentes mismas de nuestro discurso pedagógico. Nos obliga a resistir a todos los intentos de «reducir a los individuos a categorías económicas, a desenterrar y formular por medio de un trabajo crítico negativo los propios intereses y necesidades en los que poder reconocerse como fines en sí, evitando la falsa apariencia de una autonomía que todavía está por realizar" (Zamora, 2009, 45). Nos obliga a un discurso pedagógico y a una praxis educativa que pongan al otro como punto de partida y nos enseña que "el dolor del otro, del que no tiene poder, del que no tiene palabra, es también mi dolor, un dolor que es constitutivo de mi subjetividad bumana, (Mèlich, 2004, 131). Que Auschwitz no se repita es la primera de todas las exigencias que la educación debería plantearse (Adorno, 1993). "No se han hecho bien las cosas sino cuando de verdad han hecho falta" (Ortega y Gasset, 1973, 49). Creemos que ha llegado el momento de "hacer bien las cosas", de construir un nuevo pensamiento y un nuevo lenguaje pedagógicos más apegados a las circunstancias sociohistóricas de nuestros conciudadanos. No pretendemos, en este trabajo, ofrecer soluciones a la situación de ruptura entre nuestro discurso pedagógico y el mundo de la vida (lebenswelt). Nos limitamos a señalar un camino que haría posible una educación "distinta", pensada en y desde el otro, desde su situación histórica.

\section{UNA DEUDA PENDIENTE}

El discurso pedagógico ha estado muy alejado de la experiencia. Ha olvidado o ignorado que nunca se educa si no es en el envolvimiento de una tradición y de una lengua, es decir, en una cultura como forma de entender y realizar la existencia humana. Ha olvidado que el ser humano es un ser gramatical, y que sólo se entiende a partir de su herencia gramatical (Mèlich, 2010). Por ello, "vincular la educación a la experiencia de la vida real de nuestros educandos se convierte en un axioma educativo. No hay lenguaje y praxis educativos si no hay lenguaje de la experiencia. Inevitablemente, hablar de educación es hablar de experiencia. Sin ella, el discurso educativo se torna en discurso vacío, en retórica inútil» (Ortega, 2010, 24).

El discurso pedagógico, al menos en España, no ha sido sensible a las dolorosas experiencias de su tiempo. Ha habido un silencio cómplice sobre los problemas y situaciones que dañan gravemente la dignidad y la libertad de nuestros conciudadanos, víctimas de la exclusión social, pobreza, xenofobia, fundamentalismo religioso, nacionalismo totalitario... Estas situaciones "anómalas" no han merecido 
una reflexión ética y pedagógica. La historiografía del SITE (Seminario Interuniversitario de Teoría de la Educación) y del CiTE (Congreso Interuniversitario de Teoría de la Educación) así lo acredita. Se piensa, quizás, que estas circunstancias no son un problema "nuestro", sino un problema de la humanidad. Instalados en un mutismo inmoral nuestro discurso asiste impasible al espectáculo de la desposesión de sus derechos a ciudadanos inermes, víctimas de la arbitrariedad del poder. Los pobres y excluidos de la vida social, los inmigrantes y diferentes culturales, "los otros" que no hablan nuestra lengua, a quienes hemos estigmatizado como "incivilizados" (Adorno, 1975) han sido ignorados o simplemente no han existido en nuestro discurso. ¿Por qué se ha llegado a esta situación? Quizás tengamos que encontrar la explicación a esta "anomalía" en una antropología y una ética de la "lejanía y del alejamiento" que ha facilitado que el hombre pueda hacer daño al hombre hasta llegar a convertirlo en un exhombre (Duch, 2004), antropología y ética que se han negado a abrirse a la experiencia, incapacitándole para ayudar a los educandos a dar una interpretación de los acontecimientos de su tiempo.

La pedagogía se ha apropiado, en su discurso y en su praxis, de las ideas de la Ilustración. El sufrimiento humano es ajeno al pensamiento ilustrado; y un pensamiento que no pone en la cancelación del sufrimiento su telos queda reducido a una función más del engranaje social, a una eficaz evasión compensadora de la injusticia (Zamora, 2004). El desarrollo tecnológico y su aplicación en los más sofisticados métodos de dominio, la universalización del control social, el darwinismo social como ideología dominante, el sesgo totalitario de los grupos políticos nacionalistas, el notable déficit de normas morales en la gestión administrativa son elementos específicos de la modernidad puestos al servicio de los aparatos de poder que hacen posible la aniquilación jurídica y moral del diferente, contraviniendo las afirmaciones de universalismo y cosmopolitismo moderno. Hemos aceptado sin reparos que los mecanismos formales que garantizan el funcionamiento democrático de nuestras sociedades son suficientes para asegurar las libertades y las condiciones de igualdad de todos los ciudadanos. Los hechos, sin embargo, nos confirman que el reconocimiento formal de los derechos de los ciudadanos no nos garantizan la igualdad y la libertad políticas, ni nos inmunizan frente al despotismo ilustrado, el nacionalismo excluyente, el fundamentalismo religioso y las más variadas formas de exclusión social.

Al inicio de este siglo nos resulta difícil entender cómo ha podido suceder que un siglo como el pasado que ha hecho de la razón, la libertad, la igualdad y la dignidad humanas los pilares fundamentales de sus instituciones y de su organización social no haya podido impedir que unos seres humanos, "capaces de llorar y emocionarse por el sufrimiento del otro en el transcurso de una evocación literaria, quedasen impertérritos frente a su propio crimen" (Bárcena y Mèlich, 2000, 126); nos es difícil entender por qué la humanidad, en vez de alcanzar un estado verdaderamente humano, se hunde en una nueva forma de barbarie (Horkheimer y Adorno, 2004). Es extraño que esta inquietante pregunta no se haya formulado, con más frecuencia, en las convenciones y congresos sobre educación, al menos 
en España; que se hayan silenciado las situaciones de violación de los derechos humanos en nuestra sociedad "civilizada", como si el mal fuese una cuestión del pasado, o se debiese a circunstancias sociopolíticas ya definitivamente superadas; que nuestro discurso pedagógico haya puesto su atención sólo en el hombre "ideal" de la Ilustración, sin biografía ni contexto.

Este "olvido" no se ha debido a un deliberado propósito de "mirar para otro lado", de pasar página. Consideramos, más bien, que nuestra amnesia está vinculada a un discurso en educación que hunde sus raíces en una antropología y en una ética que han hecho del logos su punto arquimédico. "La historia de la cultura, de la filosofía y de la ciencia occidental es la historia del desarrollo de un logos que no se contempla más que a sí mismo" (Mèlich, 2004, 43), y este logos no ha sido capaz de expulsar la ignominia de nuestra sociedad (Chalier, 1995). El imperio de la razón, alejada de toda posible contaminación de la experiencia, ha dado soporte teórico a toda nuestra reflexión y práctica moral. Y esta huida al "mundo de las ideas", alejado de la opacidad de la experiencia de la vida, se ha demostrado del todo insuficiente para expulsar la ignominia y dar a los hombres el sentido de lo humano (Chalier, 1995). La corporeidad, la contingencia, la vulnerabilidad del ser humano es un escenario muy alejado del "reino de las ideas" en el que se ha instalado el discurso y la praxis educativa. Y una ética que desconoce e ignora la "circunstancia" del ser humano (corpóreo, situacional, ambiguo, temporal) incapacita al hombre para insertarse en "su" mundo y convivir con el otro, le hurta la forma de responder de él y ante él, instalado en un "teatro metafísico" en el que sólo responde no ante el otro o del otro, sino ante los "grandes principios". Es ésta una ética indolora, ajena a lo que acontece en la vida humana, una ética incapaz de dar cuenta de las relaciones del hombre con el mundo y con los demás. Es una ontología que sólo se reconoce deudora de los "grandes principios".

No es casual que, durante muchos años, nuestro discurso ético en educación haya tenido como soporte al paradigma kantiano, refractario a toda contaminación con los sentimientos y situaciones concretas de los individuos (Ortega, 2004). Y tampoco es extraño que el "mundo" de los centros de enseñanza sea una simple caricatura de lo que acontece fuera de las aulas. El "mundo de la vida" (lebenswelt) y la educación han sido realidades mutuamente ignoradas, cuando no contrapuestas. Este tipo de discurso pedagógico, centrado en la transmisión de saberes, ha dado lugar a un divorcio entre la educación moral del individuo y su formación intelectual. De aquí el interés creciente en asegurar el aprendizaje de aquellos saberes que se consideran prioritarios para la formación del alumno. La búsqueda de resultados, la eficacia, la rentabilidad y el control de los procesos de aprendizaje son términos omnipresentes en el discurso educativo que definen una determinada orientación de la educación (Mínguez, 2010). El reciente discurso sobre las "Competencias" en la educación no escapa a este enfoque pragmático que orienta toda la acción educativa hacia la obtención de resultados evaluables, traducidos en un saber hacer, o qué y cuándo hacer (González y otros, 2011). Es verdad que simultáneamente hay "otro discurso" sobre los valores en educación, pero éste es 
un discurso "paralelo" escasamente operativo para incidir en los procesos educativos, pues cualquier propuesta de valores sucumbe a la filosofía imperante que le asigna a la educación la adquisición de aquellas competencias técnicas e intelectuales que, se supone, demanda la sociedad del desarrollo y del progreso. Esta praxis educativa reproduce fielmente la imagen "idealista" del hombre que ha dado lugar a una educación indiferente y alejada de lo que acontece en el entorno del individuo. A nuestro discurso pedagógico podrían aplicarse las palabras que Levinas $(1993,82)$ dedica al humanismo occidental "al establecerse en la memorable ambigüedad de las bellas letras, de las "almas bellas", sin contacto con la realidad de la violencia y de la explotación". Desde este modo de entender la educación, los otros y el mundo entran en un segundo plano. Es la pedagogía de la irresponsabilidad y el desamor. Y ya, a la vista de la experiencia de este último siglo, no nos es permitido seguir practicando como adecuadas las acciones educativas orientadas por la idea de autonomía del sujeto racional y emancipado que le ha venido sirviendo de justificación al supuesto proyecto emancipador de la modernidad (Zamora, 2009).

\section{3. ¿QUÉ ÉTICA, QUÉ EDUCACIÓN?}

Todo discurso educativo "viene de algún sitio" y "va hacia algún lugar", descansa sobre unos presupuestos éticos y antropológicos y se plasma en unos modos concretos de responder a los retos actuales del ser humano, en unos determinados modelos de realización personal. La ética no es un discurso neutro o indiferente y condiciona una praxis educativa determinada (Ortega, 2004). Nuestro discurso sobre la ética y la educación trasciende el ámbito estricto de una deontología profesional del educador (García, Jover y Escámez, 2010), como podría ser la del médico, abogado, investigador, agricultor, empresario, etc. Independientemente de que el educador sea un buen profesional, y se ajuste en su práctica educativa a los principios deontológicos que exige su profesión; o que el educador esté atento a las necesidades del educando (Noddings, 2005), sea afectuoso y comprensivo con sus alumnos, estaríamos tan sólo ante una metodología a emplear en educación, pero no habríamos tocado el corazón mismo de la acción educativa. Para nosotros, la educación es y se define en sí misma como un acto ético, un encuentro de dos que se traduce y es, en su misma raíz, acogida y responsabilidad (Ortega, 2004). Sin ética no es posible hablar de educación. Su carácter ético no le sobreviene, como un añadido que haga plausible la intervención educativa. La eticidad atraviesa de principio a fin, en su misma esencia, toda la acción educativa. La bondad o no de unas determinadas estrategias que hagan plausible la intervención educativa, o el cumplimiento de unas normas que hagan del ejercicio profesional una actividad respetuosa de los derechos de los individuos y de la sociedad, son cuestiones que "sobrevienen" a la acción misma de educar, son sólo "condiciones" exigibles de la acción educativa. Más allá de una actividad técnica o profesional, la educación es, en sí misma, una experiencia ética, no una relación entre profesor y alumno 
"rebosante de posibilidades morales" (Bruzzelli y Johnson, 2002). No basta con "humanizar" la educación mediante estrategias que nos acerquen al educando, que nos ayuden a comprenderlo y situarnos en su tiempo y en su espacio. El carácter ético, más bien, es una exigencia que define y constituye a la acción educativa.

En toda acción educativa hay una pregunta que se hace ineludible: ¿Quién es éste, ésta para mí? ¿Cuál es mi relación (ética) con él, con ella? Sin formularnos esta pregunta y responder éticamente a la misma no puede darse un proceso educativo, porque sin la creación de un espacio ético en la relación educativa no hay educación. Sólo cuando el educando es tratado y reconocido como "alguien", cuando se le pone rostro y nombre, se le reconoce en la singularidad de su existencia, en su situación, se puede educar.

Si toda pedagogía es deudora de una antropología y una ética, la educación como acogida y responsabilidad que aquí se propone se inspira en la ética levinasiana. Reconoce que la relación ética que le ata o vincula al otro es una relación de responsabilidad para con él, de radical dependencia del otro de la que no se puede desprender. "El sujeto es responsable de su responsabilidad, incapaz de sustraerse a ella sin guardar la huella de su deserción. El sujeto, antes de ser intencionalidad, es responsabilidad" (Levinas, 1993, 72). Y responsabilidad irrescindible, irreversible, irrecusable, sin remontarse a una elección previa; "como la obediencia a una orden que se acata antes de haberla escuchado" (Levinas, 1993, 75). En Levinas, la relación ética que sostiene el discurso no es una variedad de la conciencia cuyo radio parte del yo. Por el contrario, cuestiona el yo. Y este cuestionamiento parte siempre del otro (Levinas, 1987). Si el sujeto, como afirma Levinas, es responsabilidad, toda acción educativa debe ayudar al sujeto a ser responsable, es decir, capaz de responder no sólo al otro, sino del otro. Cuando se educa no nos limitamos a transmitir unos determinados conocimientos, destrezas o competencias, permaneciendo ajenos o indiferentes a la realidad de la vida de cada educando, a su circunstancia y contexto. Es el sujeto en todo lo que es quien es acogido, quien debe ser educado. Sólo cuando el educador se hace responsable del otro, responde a éste en su situación concreta, se preocupa y ocupa de él desde la responsabilidad, se da la educación. Por ello la educación no se entiende ni se da al margen de la ética, sin una relación responsable con el otro. Ello hace que postulemos un modelo de educación que se apoya en presupuestos éticos y antropológicos que "explican" al ser humano no como un ser en sí y para sí, propios de la ética y moral kantianas, sino como una realidad abierta al otro y para el otro, cuya realización como ser moral no está en su autonomía, "ni en un movimiento reflexivo de sí sobre sí mismo, en la conciencia de sí, sino tan sólo en el movimiento de una respuesta... a la llamada de la alteridad" (Chalier, 1995, 73). Es la dependencia y "obediencia" al otro, en la más radical heteronomía (Levinas, 1987) la que nos hace sujetos morales.

El discurso pedagógico ha sido deudor de la ética indolora kantiana hasta bien entrada la década de los ochenta. Para la ética kantiana es un claro despropósito hablar de "sentimientos y moral". Ambos son términos irreconciliables en la moral 
kantiana. La norma que debe orientar la conducta moral de un sujeto no puede estar al albur de los sentimientos de los individuos que, al ser singulares y concretos, necesariamente son contingentes y particulares y, por ello mismo, no pueden convertirse en una máxima moral (Kant, 2004). Para Kant no hay posibilidad alguna de "cohabitación" entre sentimientos y razones, entre moral y emociones.

Es muy hermoso hacer el bien por amor a los seres humanos y en aras de una compasiva benevolencia o ser justo por amor al orden, mas eso no constituye aún la genuina máxima moral de nuestra conducta, la máxima que conviene a nuestro punto de vista en cuanto seres humanos entre entes racionales, cuando con esa orgullosa presunción propia de los voluntarios nos atrevemos a situarnos por encima del pensamiento del deber y, al margen del mandato, pretendemos hacer simplemente porque nos viene en gana una cosa para la cual no precisaríamos mandato alguno. Nos hallamos bajo una disciplina de la razón y en todas nuestras máximas no tenemos que olvidar esa sumisión (Kant, 2004, 176).

Para Kant, la razón ética es ajena a la corporeidad, a la condición "natural" del hombre como ser situacional, ininteligible al margen de la contingencia y de la ambigüedad.

El desapego que Kant manifiesta hacia el sentimiento, y el papel de éste en la motivación y fundamento de la conducta moral, no representa un caso aislado entre los pensadores de su época, tiene, por el contrario, un claro precedente en la cultura de la primera modernidad. En ésta "los sentimientos se convirtieron en unos elementos "apátridas" (heimathos) que no tenían ningún lugar en una sociedad que, en todos los ámbitos de lo humano, buscaba la racionalidad y la objetividad. Como consecuencia del proceso de modernización, en el marco de la vida cotidiana los sentimientos... se volvieron invisibles e imperceptibles" (Duch y Mèlich, 2005, 231-232). No es una razón incontaminada, incondicionada y formal, capaz de formular principios universales la que ofrece garantías contra la inhumanidad. ¿De dónde sabe la razón que el ser humano tiene dignidad, que no puede ser vejado, humillado, aniquilado, etc., si no es desde la experiencia acumulada de sufrimiento y de la reacción somática frente a él elevada a conciencia que se rebela contra sus causas? "Convertir dicha dignidad en principio formal que ha de regir la conducta, al menos no ha servido para evitar las catástrofes que conforman el oscuro reverso de la historia" (Zamora, 2004, 272). Toda la experiencia del mal que hemos conocido en el pasado siglo y que, en manifestaciones distintas, nos acompaña en el presente nos ha llevado a comprender cuánto conocemos del "mal" y qué poco sabemos del "bien". De ahí que no sea posible derivar una ética desde el bien ideal, colgarla en el cielo de lo universal y esperar del individuo que camine mirando "hacia arriba", hacia los "grandes principios". Los acontecimientos que los hombres y mujeres concretos han padecido exigen a la ética descender al nivel de lo individual, a la experiencia del sufrimiento, y empezar a pensar la ética con el individuo concreto, junto a él, desde y en sus experiencias cotidianas, desde la realidad de su existencia. "La ética es una historia que comienza con la experiencia 
y que continúa con la experiencia... La ética es una narración de la historia de los seres humanos" (Tafalla, 2003, 132).

El discurso moral kantiano, hegemónico hasta décadas recientes, no "ha hecho posible "la otra moral" que asume como contenido material las condiciones socio-históricas del hombre de nuestro tiempo" (Ortega, 2006, 503), eclipsando las aportaciones de otras éticas al discurso y prácticas morales, y relegando a un segundo plano "otras miradas" hacia la moral. Hay otras respuestas distintas a las dadas en la ética kantiana a preguntas como éstas: qué es lo que nos mueve o impulsa a una conducta moral, cuál es el fundamento y contenido de la moral, etc. Hay otras antropologías que explican al ser humano no en sí y desde sí, en la autonomía o autoconciencia kantiana, sino como una realidad abierta al otro, con el otro y para el otro, y desde el otro (Levinas, 1991). Esta apertura antropológica es condición necesaria para que haya ética, pues sin relación con el otro no hay ética, es decir, responsabilidad. Hay otras éticas que abordan la conducta moral sin atender a principios abstractos o máximas universales que la justifiquen y que podrían inspirar una actuación educativa.

\section{UNA ÉTICA ENRAIZADA EN EL SENTIMIENTO}

"Uno puede lograr hacer virtuoso a un hombre mediante lecciones de moral o prédicas en tan escasa medida como todas las doctrinas estéticas, desde Aristóteles hasta nuestros días, han servido para forjar un solo poeta... Pues el concepto, que ya descubrimos infructuoso para el arte, se muestra igualmente estéril para la auténtica e íntima esencia de la virtud" (Schopenhauer, 2001, 140). Este texto de Schopenhauer muestra la impotencia de la ética kantiana para mover a un sujeto a una vida moral. Es el sufrimiento y el dolor del otro, el sentimiento de compasión (cum-pati, padecer con) el que nos lleva a compartir su suerte, a buscar su felici$\mathrm{dad}$, no un juicio abstracto sobre la dignidad de la naturaleza humana. "La compasión, como el único móvil no egoísta, es también el único auténticamente moral, resulta, de una forma extraña y hasta casi incomprensible, paradójica" (Schopenhauer, 1993, 255). Sólo el que compadece obra moralmente. ¿Cómo surge en nosotros la compasión y no el rechazo o indiferencia ante el sufrimiento y el dolor del otro? Schopenhauer no encuentra un argumento o soporte "racional", más bien se muestra "Sorprendido" ante este hecho empírico. Es un proceso "misterioso" cómo el ser humano puede sentir como suyo el sufrimiento del otro. «Ese proceso es, lo repito, misterioso: pues es algo de lo que la Razón no puede dar ninguna cuenta inmediata y cuyos fundamentos no se pueden averiguar por vía de experiencia. Y, no obstante, es cotidiano" (Schopenhauer, 1993, 254). Para Schopenhauer la moral es an-árquica, no está referida a un principio previo universalmente válido, no demanda el respaldo de una ley universal que nos dicte qué debemos hacer en situaciones concretas. "Poseemos una consciencia moral, una conciencia en sentido estricto. Pero dicha consciencia moral no ostenta en modo alguno la forma de un imperativo, de un dictado relativo a lo que uno debe hacer y a lo que uno debe dejar 
de hacer... Sin embargo, nadie dará con semejante precepto, mandato o deber en el seno de nuestra consciencia" (Schopenhauer, 2001, 3). La conducta moral no acontece por "lo que pensamos" acerca de ella, sino porque nos sentimos conmovidos, padecemos en nosotros, la situación real de aquel que tenemos delante. "La resistencia a aceptar el sufrimiento del otro o la no-indiferencia hacia el necesitado constituye no sólo el impulso para la conducta moral, sino que la ayuda. El hacerse cargo del otro, la caridad o agapé, en palabras de Schopenhauer, es el contenido mismo de la moral, porque sólo esta conducta tiene valor moral" (Ortega y Mínguez, 2007, 131). Pero tampoco es un impulso ciego o un sentimiento irracional. Brota de la experiencia material de sufrimiento del individuo concreto.

Para Horkheimer y Adorno sólo puede haber moral si ésta está referida, en su contenido, a las experiencias reales de la vida de los seres humanos en las circunstancias en las que les ha tocado vivir; circunstancias que, para Horkheimer y Adorno (1994), están inexorablemente vinculadas a la experiencia límite del Holocausto. "No cabe la vida justa en la vida falsa", escribe Adorno (2004, 44), afirmación que puede parecer exagerada, pero responde a circunstancias que no pueden ser negadas, y nos advierte de la endeblez de un individualismo moral que no fue un dique sólido para detener la "barbarie". La impasibilidad y la indiferencia de la moral idealista es una categoría histórica emparentada con la catástrofe. Representa el principio sin el que no hubiera sido posible Auschwitz. En Dialéctica negativa, Adorno (1975) hace una dura crítica al discurso moral idealista, que más que ofrecer una base para la construcción de una sociedad justa es, por el contrario, su producto y cumple una función legitimadora de la misma. En el origen de esta moral (adorniana) no está la razón, como la entiende la moral idealista, sino el sentimiento, el "pathos", el anhelo de justicia que ponga fin al sufrimiento de los excluidos de la felicidad a la que tienen derecho; está la urgencia de solidaridad con los miserables. En esta moral no es la razón la que nos inclina a obrar según el deber, pero tampoco es un sentimiento irracional. Es una afección en la conciencia por el reconocimiento de los otros en sus circunstancias concretas (Ortega, 2006, 513). Cuando compadecemos, cuando nos hacemos cargo del otro en su circunstancia concreta, no nos mueve una razón abstracta de la dignidad de la naturaleza humana, sino un sentimiento "cargado de razón" que intentar justificarlo con argumentos desde la moral idealista (dignidad de la naturaleza humana) constituiría un sarcasmo para todos aquellos ultrajados a quienes se les ha negado la dignidad (Ortega, 2006). ¿Por qué tiene que justificar el explotado su derecho a ser tratado como persona? ¿Por qué el inocente tiene que justificar su inocencia? Más bien es quien explota el que debe argumentar o dar explicaciones de su conducta contra los derechos del otro. No es el sentimiento moral de compasión, el anhelo de justicia, sino la realidad inmoral la que necesita una fundamentación "racional" (Horkheimer, 2002).

Hay otro discurso ético, alejado de la moral idealista kantiana, que sitúa en la demanda del otro el origen de la moral. Es la ética de la alteridad y de la hospitalidad, "la ética del rostro, del huérfano y de la viuda", en expresión de Levinas; 
la ética de la com-pasión, es decir, la ética del hacerse cargo del otro (Levinas, 1991). Para Levinas, la moralidad no se funda en la decisión racional y libre de cada individuo, sino en la voluntad de acoger al otro de tal modo que él prevalezca sobre el propio yo (Levinas, 1987). En la ética levinasiana «la apertura al otro y la comunicación con él no son plenas más que cuando se viven como un estar asignado o confinado a la responsabilidad por él" (Chalier, 1995, 92). En esta ética, el sujeto sólo llega a ser sujeto moral en la medida en que su identidad se rompe y se transforma, se quiebra por la presencia del otro (Mèlich, 2001). El yo se ofrece como un punto de desinterés en el ser, como un punto de responsabilidad extrema, susceptible de llegar hasta la expiación por el otro (Levinas, 1993). En este acto de descentramiento del propio yo, el sujeto se hace responsable del otro, es decir, sujeto moral. En esta ética nos constituimos en sujetos morales, no en un ejercicio de autonomía, sino en la dependencia del otro, cuando respondemos a su demanda, cuando nos hacemos cargo de él desde la más radical heteronomía (Levinas, 1991), cuando obedecemos al mandato inapelable del rostro del otro. "El No Matarás es la primera palabra del rostro. Ahora bien, es una orden. Hay, en la aparición del rostro, un mandamiento, como si un amo me hablase. Sin embargo, al mismo tiempo, el rostro del otro está desprotegido; es el pobre por el que yo puedo todo y a quien todo debo" (Levinas, 1991, 83). La indigencia escrita en el rostro del otro me emplaza como responsable ya desde un principio, aun a mi pesar, me toma como rehén y me interpela, aun cuando el otro se niegue a reconocerme (Chalier, 1995). Es el rostro del "huérfano y de la viuda", en palabras de Levinas, del sufriente de nuestros días, el que nos impulsa a responder, con urgencia e impaciencia, frente a la injusticia. "Ambas (impaciencia y justicia) se resisten a un aplazamiento de la acción por motivos de racionalización o fundamentación. La superación práctica del sufrimiento no tolera ningún aplazamiento" (Zamora, 2004, 266). Y es la necesidad de la eliminación del sufrimiento el único fundamento posible de la moral, pues ésta no es otra cosa que la resistencia contra la inhumanidad (Adorno, 2004).

\section{UNA EDUCACIÓN PARA RESPONDER DEL OTRO}

"... me parece muy claro que el pedagogo o la pedagoga de nuestros días conscientes de su misión de procurar elementos críticos, no pueden limitarse a ser unos buenos "profesionales". Si desean procurar a sus educandos los criterios para que a lo largo y ancho de su vida sean capaces de ejercer el arte de la crítica, tendrán que ser además testimonios" (Duch, 2004, 193). La ética de Levinas sólo puede ser soporte de una educación que se traduce en acogida y reconocimiento del otro. La ética del pensador lituano no nace de una reflexión de la dignidad de la persona, no nace de la razón, sino de un mandato inapelable del rostro doliente del otro, del sufrimiento del otro. Es una ética heterónoma, compasiva, nacida de la experiencia; es una mirada siempre atenta al rostro del otro, al que no puede rechazar apelando al silencio o a la indiferencia. 
La pedagogía de la acogida no se identifica con la pedagogía de la "instrucción", con la enseñanza-aprendizaje de saberes y destrezas en la que se ha convertido la enseñanza de nuestros centros escolares. Se olvida, con frecuencia, que entre el "instruir-explicar" y el "acoger" hay una diferencia de naturaleza. En la pedagogía de la acogida del otro la relación que se establece entre educador y educando no es propiamente una relación "técnica", apoyada en la competencia profesional del educador, sino una relación ética sustentada en la experienciatestimonio del mismo. Lo que el educador transmite no es una explicación de los acontecimientos del mundo, sino su experiencia vital, su modo de relacionarse y vivir con los otros, de resolver el problema de su existencia con los otros. Y porque es «transmisión testimonial, el maestro no convierte en ejemplo su experiencia, ni la transmite para que sea repetida o tomada como modelo" (Mèlich, 2010, 278).

¿Cómo "explicar" a los educandos qué es la compasión y cómo nos compadecemos, qué es y cómo respondemos a la demanda del otro sufriente; qué es acoger al otro y cómo nos hacemos cargo de él; cómo se vive sin ser indiferente o guardar silencio ante las situaciones de sufrimiento y violencia de los demás? Esta educación se hace a través del contagio, de la mímesis; no ha lugar a la "explicación". La educación idealista-cognitiva, por el contrario, se mueve en el ámbito de la lógica y del discurso; la educación de la acogida se plasma a través de la experiencia. Ambas se apoyan en modelos o paradigmas distintos. Por eso decimos que hay "experiencias" que no se pueden "explicar".

Si la educación es responsabilidad y acogida, ésta se da siempre a una persona concreta que vive en una situación también concreta. No se acoge, ni se educa, a un ser ideal, sin historia ni contexto. Se acoge a un ser humano atrapado por su tiempo y por su espacio, por su "circunstancia". La "circunstancia" de cada ser humano forma parte de su contenido humano, no se la puede quitar de encima. "No hay posibilidad alguna de lo "humano" al margen de las relaciones, de los condicionantes, de las raíces que cada uno tiene con el mundo, con su mundo" (Mèlich, 2010, 105-106). Por ello no puede haber un discurso y praxis educativos sin tiempo ni espacio. Necesariamente es un discurso situado, histórico. "En educación no contemplamos al hombre universal, sino a este individuo concreto que vive, siente y piensa en un espacio y tiempo también concretos" (Ortega, 2010, 18). El carácter histórico de la educación hace que la acción de educar sea una tarea original, singular, no estandarizada y siempre inacabada e incierta; que no se pueda educar si no se conoce la situación y el contexto en que vive el educando, ni hacer abstracción de las características singulares de éste, pretendiendo hacer una educación de validez universal.

La pedagogía de la acogida tiene como soporte teórico a la ética de la compasión. El que compadece no tiene en cuenta el origen, lengua y raza del compadecido. Es la "presencia inquietante" del otro, de cualquier otro, la que demanda una respuesta incondicional y urgente. Esta ética de la compasión es la forma en la que los seres humanos respondemos ante los demás, del otro y ante el otro. "Es la respuesta que damos al otro que nos sale al encuentro" (Mèlich, 2010, 95). Si se es 
sujeto moral cuando se responde a la demanda del otro, cuando se compadece y se acoge al otro, la educación, entonces, no es más que un largo aprendizaje para la acogida, para vivir éticamente, es decir, en la responsabilidad. Y este aprendizaje se hace, necesariamente, desde y en la experiencia. "La educación es propuesta, ofrecimiento respetuoso, testimonio de un modo de vida, hecho desde la experiencia de un estilo ético de vida" (Ortega, 2010, 21). Esta pedagogía de la acogida está muy lejos de la competencia de un experto y más cerca del maestro que sólo señala, en la incertidumbre y el temor, el camino de la acogida, de la respuesta ética al otro. No es una pedagogía que tenga como finalidad principal "fomentar el desarrollo de personas competentes, bondadosas, cariñosas y a las que es fácil amar" (Noddings, 2002, 94), ni una pedagogía del tacto volcada en el afecto hacia el otro (Van Manen, 2004). No se trata de acudir a nuevas prácticas o recursos didácticos; no son nuevos ropajes o nuevas formas en nuestra práctica educativa lo que una pedagogía de la acogida nos demanda. Es más bien una nueva forma de "mirar" al hombre y al mundo, una manera distinta de acercarnos al ser humano y de estar presente en el mundo. Se trata de una filosofía de la educación y de la vida que nos hace cómplices de todo ser humano, empezando por el que tenemos más cerca. Es una pedagogía que va más allá de una relación afectiva entre educador y educando, que nos "obliga", incluso a nuestro pesar, a responder del otro, a hacernos cargo de él si queremos vivir en dignidad. Es una pedagogía de la renuncia y del abandono del propio yo para afirmar la primacía del otro en un acto de "obediencia" a quien es más que yo (Levinas, 1991). Estar atento a los acontecimientos de nuestro tiempo, ser sensible a los sufrimientos del otro, no viene de la mano de una pedagogía idealista, instalada en una filosofía de los "grandes principios". Es más bien resultado de una ética de la situación que asume la respuesta a las necesidades del otro como condición irrenunciable de la vida ética, es decir, responsable. No hay posibilidad de una vida "humana" sin los lazos de responsabilidad con la suerte de los otros en su condición ineludible de "seres dolientes", porque "sólo siendo responsables del otro, que siempre es un otro concreto, un otro de carne y hueso: sólo respondiendo de su vida y de su muerte, de su gozo y de su sufrimiento, accedemos a la "humanidad" (Mèlich, 2004, 41). Es esta ética de la compasión, como soporte de una pedagogía de la responsabilidad, la que nos puede ayudar a saldar nuestra deuda pendiente con las víctimas de la arbitrariedad del poder.

\section{REFERENCIAS BIBLIOGRÁFICAS}

Adorno, Th. W. (1975) Dialéctica negativa. Madrid, Trotta.

- (1993) La educación después de Auschwitz, en Consignas. Buenos Aires, Amorrortu.

- (2004) Minima Moralia. Madrid, Akal.

BÁrcena, F. y Mèlich, J. C. (2000) La educación como acontecimiento ético. Barcelona, Paidós.

Bauman, Z. (1997) Modernidad y Holocausto. Madrid, Sequitur. 
Bruzzeldi, C. A. y Johnson, B. (2002) The Moral Dimensions of Teaching. Language, Power and Culture in Classroom Interaction. N. York/London, Routlege Falmer.

CHALIER, C. (1995a) La utopia de lo bumano. Barcelona, Riopiedras.

- (1995b) Levinas, la utopía de lo humano. Barcelona, Riopiedras.

Duch, Ll. (2004) Estaciones del laberinto. Barcelona, Herder.

DuCH, Ll. y MÈLICH, J. C. (2005) Escenarios de la corporeidad. Madrid, Trotta.

García, R.; Jover, G. y Escámez, J. (2010) Ética profesional docente. Madrid, Síntesis.

GONZÁlEZ, A. y otros (2011) El aprendizaje por competencias. Valencia, Brief Edit.

Habermas, J. (1996) Textos y contextos. Barcelona, Ariel.

Horkheimer, M. (2002) Crítica de la razón instrumental. Madrid, Trotta. Trad. de J. Muñoz.

Horkheimer, M. y Adorno, Th. W. (1994) Dialéctica de la Ilustración. Madrid, Trotta. Trad. de J. J. Sánchez.

KANT, E. (2004) Crítica de la razón práctica (3. e reimpresión). Madrid, Alianza. Trad. de R. Rodríguez Aramayo.

- (2005) Fundamentación para una metafísica de las costumbres (1. a reimpresión). Madrid, Alianza. Trad. de R. Rodríguez Aramayo.

LEVINAS, E. (1987) Totalidad e infinito. Ensayo sobre la exterioridad. Salamanca, Sígueme.

- (1991) Ética e infinito. Madrid, Visor.

- (1993) Humanismo del Otro Hombre. Madrid, Caparrós.

MÈLICH, J. C. (2001) La ausencia del testimonio. Barcelona, Anthropos.

- (2004) La lección de Auschwitz. Barcelona, Herder.

- (2010) Ética de la compasión. Barcelona, Herder.

Mínguez, R. (2010) La escuela hoy en la encrucijada. Hacia otra educación desde la ética de E. Levinas. Teoría de la Educación. Revista Interuniversitaria, vol. 22, 2, 43-61.

NodDings, N. (2002) Educating moral people. A caring alternative to character education. N. York, Teacher College Press.

- (2005) Identifying and responding to needs in education. Cambridge Journal of Education, vol. 35, n.․ 2, 147-159.

OrtegA, P. (2004) Moral education as pedagogy of alterity. Journal of Moral Education, vol. 33 (3), 271-291.

- (2006) Sentimientos y moral en Horkheimer, Adorno y Levinas. Revista Española de Pedagogía, n. $.235,503-524$.

- (2010) Educar es responder a la pregunta del otro. Edetania, n.. 37, 13-33.

Ortega, P. y Mínguez, R. (2007) La compasión en la moral de A. Schopenhauer. Sus implicaciones pedagógicas. Revista Española de Pedagogía, vol. 17, 117-137.

Ortega y Gasset, J. (1973) Obras Completas, vol. VI. Madrid, Revista de Occidente.

Schopenhauer, A. (1993) Los dos problemas fundamentales de la ética. Madrid, Siglo XXI. Trad., introd. y notas de P. López de Sta. María.

- (2001) Metafísica de las costumbres. Madrid, Trotta. Traducción y edición de R. Rodríguez Aramayo.

Tafalla, M. (2003) Recordar para no repetir: El nuevo imperativo categórico de T. W. Adorno, en Mardones, J. M. y Mate, R. (eds.) La ética ante las víctimas. Barcelona, Anthropos, 126-154.

Van Manen, M. (2004) El tono en la enseñanza. Barcelona, Paidós.

Zamora, J. A. (2004) Theodor W. Adorno. Pensar contra la barbarie. Madrid, Trotta.

- (2009) Th. W. Adorno: aportaciones para una teoría crítica de la educación. Teoría de la Educación. Revista Interuniversitaria, vol. 21, 1, 19-48. 